\title{
Evaluation of abnormal uterine bleeding with transvaginal sonography and hysteroscopy in perimenopausal women
}

\author{
Jaya Choudhary*, Veena Acharya, Monika Jain
}

Department of Obstetrics and Gynecology, Mahatma Gandhi Medical College and Hospital, Jaipur, Rajasthan, India

Received: 12 June 2017

Accepted: 08 July 2017

\section{*Correspondence:}

Dr. Jaya Choudhary,

E-mail: jayach2003@rediff

Copyright: (C) the author(s), publisher and licensee Medip Academy. This is an open-access article distributed under the terms of the Creative Commons Attribution Non-Commercial License, which permits unrestricted non-commercial use, distribution, and reproduction in any medium, provided the original work is properly cited.

\begin{abstract}
Background: Abnormal uterine bleeding is defined as any deviation from the normal menstrual cycle this include change in regularity, frequency of menses, duration or amount of bleeding during or in between periods. Objective of present study was to evaluate abnormal uterine bleeding with transvaginal sonography and hysteroscopy in perimenopausal women.

Methods: This study is conducted on women presenting to the gynecological OPD with complain of abnormal uterine bleeding in perimenopausal age group. A total of 50 patients were subjected to transvaginal sonography and Diagnostic hysteroscopy.

Results: On TVS, out of total 50 patients, 50\% patient showed normal endometrial finding. 24\% Patient showed Endometrial hyperplasia, 14\% Endometrial Polyp, $8 \%$ Submucosal fibroid, 4\% Adenomyosis. On TVS, out of total 50 patient, $50 \%$ patient showed normal endometrial finding. 24\% Patient showed endometrial hyperplasia, $14 \%$ endometrial Polyp, 8\% submucosal fibroid, 4\% adenomyosis. Out of total 50 patients, 28 (56\%) showed normal endometrial finding. $20 \%$ cases showed endometrial Hyperplasia, 16\% showed endometrial Polyp, 8\% showed submucosal fibroid. Sensitivity, specificity, PPV, NPV of endometrial hyperplasia $-81.81 \%, 92.3 \%, 75 \%, 94.73 \%$ respectively.

Conclusions: Transvaginal sonography has a moderate diagnostic accuracy in detecting endometrial hyperplasia and other intrauterine pathology. TVS is safe, acceptable and easily available \& is noninvasive. It should be used as 1 st line diagnostic tool in patients with AUB in perimenopausal women. Hysteroscopy has important tool in the diagnosis of various endometrial and intrauterine lesions TVS and hysteroscopy should be employed hand in hand in evaluation of AUB.
\end{abstract}

Keywords: AUB, Hysteroscopy, TVS

\section{INTRODUCTION}

Abnormal uterine bleeding is defined as any deviation from the normal menstrual cycle this include change in regularity, frequency of menses, duration or amount of bleeding during or in between periods. ${ }^{1}$ AUB is responsible for $20-30 \%$ of patient who attend gynaec outpatient department amongst women in reproductive age group and $50 \%$ in a perimenopausal women and significantly impacting quality of life and imposing financial burden. ${ }^{2,3}$ The International Federation of Gynecology and Obstetrics working group on menstrual disorders has proposed a classification system (PALMCOEIN) for causes of the AUB in women. ${ }^{4}$ There are nine main categories, which are arranged according to the acronym PALM-COEIN: Polyp; adenomyosis; leiomyoma; malignancy and hyperplasia; coagulopathy; 
ovulatory dysfunction; endometrial; iatrogenic; and not yet classified.

According to the proposed classification system, nonspecific term like dysfunctional uterine bleeding should be abandoned and more than one etiology can be responsible in same patient. Among all, fibroid and polyp are one of the most common causes which are responsible for anatomical causes of AUB and approximately $20-40 \%$ women are affected. ${ }^{5}$

AUB in perimenopausal women demonstrated prevalence of endometrial hyperplasia (11.8\%), polyp (4.2\%) and adenocarcinoma as (5.5\%) respectively. ${ }^{6}$ Endometrial hyperplasia is a known precursor for endometrial carcinoma and it can progress to more severe pathology which is time related. Less than $2 \%$ of hyperplasia without atypia progress to endometrial carcinoma in $23 \%$ over a mean duration of 4 years., ${ }^{7,8}$

The incidence of hyperplasia and cancer are more common in perimenopausal women with AUB. $14 \%$ women with recurrent anovulatory cycles develop hyperplasia or cancer. ${ }^{9}$ Malignancy is important in periand postmenopausal women but also in women over age 35 with a history of chronic anovulation or obesity and in women ages 18 to 35 who have risk factors for endometrial cancer.

TVS is an inexpensive, non-invasive and a convenient way to assess the uterine pathology Therefore, it is recommended as a 1st line diagnostic tool for assessing uterine pathology in perimenopausal age women presenting with AUB. Transvaginal ultrasound can be valuable aid in evaluating the woman presenting with complaints of abnormal vaginal bleeding by demonstrating anatomical abnormality not discernible on pelvic examination such as small cyst and leiomyoma and in evaluating the endometrium in term of thickness and ovulatory and hormonal status of the endometrium.

In perimenopausal women TVS shows ET of less than 5 $\mathrm{mm}$, the probability of the woman having endometrial cancer is $1.7 \%$ and it is $0.8 \%$ when the cut-off is taken as $4 \mathrm{~mm}$. Transvaginal ultrasound detects intracavitary abnormalities like uterine tumors, polyps, and endometrial and myometrial abnormalities with a sensitivity of $60-92 \%$ and a specificity of $62-93 \%$ in perimenopausal women. ${ }^{10}$

TVS is not $100 \%$ sensitive for diagnosing endometrial polyps and other small lesions, examination with other imaging techniques like saline infusion sonohysterography (SIS) or hysteroscopy should be considered. Another limitation of ultrasound is that it cannot always reliably distinguish between benign proliferation, hyperplasia, polyps, and cancer, and in 5$10 \%$ of women with postmenopausal bleeding, the endometrium cannot be identified on TVS, these women need further evaluation with more sensitive techniques.
Hysteroscopy directly evaluate the uterine cavity which is reliable method for investigating women with abnormal uterine bleeding and is easy to perform and widely available in our setup. Hysteroscopy can accurately detect endometrial hyperplasia, endometrial polyp, submucosal myoma and endometrial atrophy. Hysteroscopy is recommended to further evaluate the endometrium in perimenopausal women with abnormal bleeding when the endometrial echo is normal on transvaginal sonography.

Hysteroscopy guided biopsy is considered the gold standard for assessing the endometrium, hysteroscopy is more sensitive than TVS and $\mathrm{d}$ and $\mathrm{c}$ which is performed blindly. With adavancement in hysteroscope technique and equipment, hysteroscopy has now become very easy to perform on OPD basis with minimal anesthesia. In this study after detail clinical and physical examination TVS and hysteroscopy was done in women of perimenopausal age group with AUB and compare the sensitivity, specificity and efficacy of TVS and hysteroscopy in diagnosis and to correlate the TVS and hysteroscopy finding with histopathology.

Objectives of present study were to estimate the diagnostic accuracy of two dimensional transvaginal ultrasound and hysteroscopy in evaluation of uterine cavity lesion in perimenopausal women with abnormal uterine bleeding and to compare the sensitivity and specificity of transvaginal and hysteroscopy and correlate the efficacy of both in diagnosing intrauterine pathology in abnormal uterine bleeding.

\section{METHODS}

This Prospective study is conducted in department of Obstetrics and Gynecology in Mahatma Gandhi Hospital, Jaipur from feburary 2015 to October 2016. This study was done on women presenting to the gynecological OPD with complain of abnormal uterine bleeding in perimenopausal age group were invited to participate in the study. The inclusion and exclusion criteria were applied and the women who were eligible to participate and who give written consent were enrolled in the study. A total of 50 women who met the inclusion criteria were selected and after explaining the procedure, the consent form explained in their own language was signed.

\section{Inclusion criteria}

Patient having following characteristic were included

- $\quad$ Perimenopausal age group (40-55)

- Having abnormal uterine bleeding

- Uterus less than 12 weeks size.

\section{Exclusion criteria}

- Acute pelvic infection

- Uterus more than 12-week size 
- Pregnant women

- Vaginal or cervical cause of bleeding

- Bleeding disorder

- Any drug intake

After selecting the patients who fulfill the eligibility criteria in the OPD detailed clinical history, obstetrical and gynecological history taken and detail clinical examination was done as per Proforma. The obstetrical history include parity, mode of delivery was taken. A detail menstrual history regarding the cycle length, no of days of menstruation and the type of abnormal bleeding was taken. Per speculum examination was done to note abnormal discharge, erosion, cervical hypertrophy or cervical polyp. A per vaginal examination was done to know about any uterine cervical and adenexal abnormality. Laboratory investigations including $\mathrm{CBC}$, coagulation profile, random blood sugar, liver and kidney function and pregnancy test done. All the eligible patients were subjected to transvaginal sonography. TVS was done by using $5 \mathrm{MHz}$ transvaginal probe and various sonographic parameters such as endometrial thickness, uterine pathology, adnexal and any other pelvic pathology is noted.

Diagnostic hysteroscopy is carried out to all patient of perimenopausal age group with abnormal uterine bleeding under general anesthesia. In proliferative phase endometrium is smooth and pink-white in colour, gland opening s appear as white ringed elevation surrounded with netlike vessel. In secretory phase of cycle endometrium is lush and velvety, can be mistaken for small polyp.

\section{For hysteroscopy}

- Hyperplasia- Thick hyper-vascular friable mucosa, mammilated or polypoid in appearance, further classified as simple or atypical by the pathologists

- Polyp - Soft intracavitary formation, which was easily mobilized and covered by mucosa with endometrial gland and no distended vascular network.

- Fibroid - Firm intracavitary formation with thin endometrial lining and superficial large blood vessels.
- Endometritis - Irregular proliferation of glands and the presence of chronic inflammatory cells e.g. plasma cells, macrophages, and lymphocyte in the endometrial stroma.

After Hysteroscopic evaluation biopsy for histopathological evaluation was done and it was taken as a Gold standard. After tabulating the findings of TVS and Hysteroscopy it was compared with histopathology and the sensitivity, specificity, PPV and NPV of TVS and Hysteroscopy were calculated and compared.

\section{RESULTS}

Out of 50 patients in this study ranged from 40-55 yr. mean age was year. Majority of patient were in age group of $40-44$ years $(48 \%)$ and minimum $14 \%$ in age group of 50-55 yr. In study population, 47 patients (94\%) were multiparous and primiparous and nulliparous were $2 \%$ and $4 \%$ respectively, Maximum no of cases belonged to class III $(56 \%)$. Rest of patient according to socioeconomic class were in class I (6\%), Class II (4\%), class IV (16\%) and class V (18\%) respectively.

Table 1: Distribution of cases according to the clinical presentation.

\begin{tabular}{|lll|}
\hline Bleeding pattern & No. of patients & $\%$ \\
\hline $\begin{array}{l}\text { Heavy menstrual bleeding } \\
\text { (menorrhagia) }\end{array}$ & 25 & 50 \\
\hline $\begin{array}{l}\text { Inter menstrual bleeding } \\
\text { (metro) }\end{array}$ & 9 & 18 \\
\hline $\begin{array}{l}\text { Frequent bleeding (poly) } \\
\text { Heavy prolonged bleeding }\end{array}$ & 8 & 16 \\
\hline (menometro) & 2 & 4 \\
\hline Trregular menstrual bleeding & 6 & 12 \\
\hline & 50 & 100 \\
\hline
\end{tabular}

Table 1 showed distribution of cases according to clinical presentation, out of 50 cases maximum no of patient (50\%) presented with heavy menstrual bleeding, this is revised terminology by AICOG which correspond to menorrhagia, while frequent bleeding in $(16 \%)$ of patient, intermenstrual bleeding in (18\%) and heavy prolonged bleeding in (4\%) and irregular bleeding in (12\%) of patient.

Table 2: Relation of type of bleeding and TVS findings.

\begin{tabular}{|llllll|}
\hline $\begin{array}{l}\text { Endometrial } \\
\text { thickness }(\mathbf{m m})\end{array}$ & Menstrual symptoms & IMB & Frequent & HPB & Irregular \\
\hline$<5$ & 1 & 1 & 0 & 0 & 0 \\
\hline $6-9$ & 14 & 2 & 3 & 2 & 2 \\
\hline $10-14$ & 6 & 4 & 3 & 0 & 2 \\
\hline $15-19$ & 2 & 1 & 1 & 0 & 1 \\
\hline$>20$ & 2 & 1 & 1 & 0 & 1 \\
\hline Total & $\mathbf{2 5}$ & $\mathbf{9}$ & $\mathbf{8}$ & $\mathbf{2}$ & $\mathbf{6}$ \\
\hline
\end{tabular}


Table 2 show correlation of patient's menstrual symptom with endometrial thickness. Out of 25 cases of Heavy menstrual bleeding maximum no of patient 14 had ET between 6-9 mm, 6 patient had ET between 10-14mm, 2 patient had heavy menstrual bleeding with ET $>20 \mathrm{~mm}$, on histopathology one of patient had atypical hyperplasia and one patient also had atypical hyperplasia on ET between 15-19. 9 patients of intermenstrual bleeding, 4 patient had ET between 10-14. 8 patients of frequent bleeding, 3 patient had ET between 6-9mm, 3 patients had ET 10-14mm, 1 had ET between 15-19 mm, and 1 had ET $>20 \mathrm{~mm}$. 6 patient of irregular bleeding 2 had ET 6-9 mm, 2 had ET between 10-14 $\mathrm{mm}$ and 1 patient had ET between 15-19 and 1 had ET > $20 \mathrm{~mm}$.

Table 3: Endometrial thickness on TVS in relation to histopathology.

\begin{tabular}{|lllllll|}
\hline Endometrial & Total & \multicolumn{6}{c|}{ Histopathological findings } \\
thickness & 2 & 2 & & & & \\
\hline$<5$ & 23 & 16 & 2 & 1 & 2 & 2 \\
\hline $6-9$ & 15 & 6 & 5 & 1 & 2 & 1 \\
\hline $10-14$ & 5 & & 2 & 3 & & \\
\hline $15-19$ & 5 & & 2 & 3 & & \\
\hline$>20$ & 50 & 24 & 11 & 8 & 4 & 3 \\
\hline Total & & & & & & \\
\hline
\end{tabular}

Table 3 shows different endometrial thickness on TVS in relation to histopathological findings. Out of total 50 cases, 2 patient had ET $<5 \mathrm{~mm}$ which were normal on histopathology. 23 patient showed endometrial thickness 6-9 $\mathrm{mm}$ on TVS, of which 16 cases were normal on histopathology, 2 case had endometrial hyperplasia, 1 case had polyp, 2 cases had submucosal fibroid and 2 cases had adenomyosis. 15 cases showed ET 10-14 mm, of which 6 cases were normal, 5 cases of endometrial hyperplasia, 1 case of endometrial polyp, 1 case of adenomyosis and 2 cases of submucosal fibroid were confirmed on histopathology. 5 cases showed ET 15$19 \mathrm{~mm}$. Out of which 3 cases were of endometrial polyp and 2 cases of endometrial hyperplasia. 5 cases showed
ET $>20 \mathrm{~mm}$ on TVS out of which 2 cases had endometrial hyperplasia and 3 were of endometrial polyp.

Table 4: Diagnosis of endometrial pathology in AUB patient with TVS.

\begin{tabular}{|lll|}
\hline Endometrial findings on TVS & No. of cases & $\%$ \\
\hline Normal & 25 & 50 \\
\hline Endometrial hyperplasia & 12 & 24 \\
\hline Endometrial polyp & 7 & 14 \\
\hline Submucosal fibroid & 4 & 8 \\
\hline Adenomyosis & 2 & 4 \\
\hline Total & 50 & 100 \\
\hline
\end{tabular}

Table 4 shows endometrial finding on TVS in AUB patients. It showed that out of 50 cases of AUB, majority of patients were normal $(50 \%)$ and $50 \%$ had abnormal endometrial finding. Most common abnormal finding was endometrial hyperplasia (24\%) followed by polyp $14 \%$, sub mucosal fibroid and adenomyosis $8 \%$ and $4 \%$ respectively.

Table 5: Finding of hysteroscopy compared with HPR.

\begin{tabular}{|lllllll|}
\hline Hysteroscopy & Total & \multicolumn{7}{c|}{ Hystopathological finding } \\
\cline { 2 - 5 } & N & EH & EP & SMF & A \\
\hline Normal & 28 & 22 & 3 & & & 3 \\
\hline $\begin{array}{l}\text { Endometrial } \\
\text { Hyperplasia }\end{array}$ & 10 & 2 & 8 & & & \\
$\begin{array}{l}\text { Endometrial } \\
\text { Polyp }\end{array}$ & 8 & & & 8 & & \\
\hline $\begin{array}{l}\text { Submucosal } \\
\text { Fibroid }\end{array}$ & 4 & & & & 4 & \\
\hline Grand Total & 50 & 24 & 11 & 8 & 4 & 3 \\
\hline
\end{tabular}

Table 5 shows that hysteroscopy showed 28 cases $(56 \%)$ as normal finding, of which 22 cases had normal endometrial finding, 3 cases showed endometrial hyperplasia and 3 cases had adenomyosis on histopathology.

Table 6: Diagnosis of endometrial pathology in AUB patients by TVS, Hysteroscopy and HPR.

\begin{tabular}{|lllll|}
\hline Final Diagnosis & Diagnosed by TVS & Diagnosed by Hysteroscopy & Diagnose by HPR & $\%$ \\
\hline Normal endometrium & 25 & 28 & 24 & 48 \\
\hline Endometrial hyperplasia & 12 & 10 & 11 & 22 \\
\hline Endometrial polyp & 7 & 8 & 8 & 16 \\
\hline Submucosal fibroid & 4 & 4 & 4 & 8 \\
\hline Adenomyosis & 2 & 0 & 3 & 6 \\
\hline
\end{tabular}

Out of 11 cases of endometrial hyperplasia 8 cases were correctly diagnosed by hysteroscopy and 3 cases were missed and showed normal endometrium, and 2 case misdiagnosed which were normal on histopathology. 8 cases of polyp were diagnosed by hyseteroscopy of which all had polypoidal endometrium on histopathology. 4 cases of submucosal fibroid diagnosed by hysteroscopy of which all had submucosal fibroid on histopathology.

Table 6 show Diagnosis of Endometrial Pathology in AUB Patients by TVS, Hysteroscopy and HPR. Out of 50 
cases of AUB patient, majority of patients had normal endometrial finding in $48 \%$ on histopathology followed by endometrial hyperplasia $(22 \%)$, endometrial polyp $16 \%$ and submucosal fibroid and adenomyosis less comparatively $8 \%, 6 \%$ respectively.

\section{DISCUSSION}

Abnormal uterine bleeding is most common gynecological complaint among women in perimenopausal age group.

\section{Distribution according to bleeding pattern}

In present study, analysis of patients according to bleeding pattern the most common bleeding pattern was heavy menstrual bleeding $(50 \%)$ which was comparable to the study by Pillai SS et al ${ }^{11}$. They had $46.5 \%$ patients with menstrual complaints of menorrhagia.

Arnold $\mathrm{J}$ et al ${ }^{12}$ also had Heavy menstrual bleeding (HMB) in maximum no. of cases $(43.7 \%)$. Shobhita GL et al showed menorrhagia in $(40 \%)$ of cases. ${ }^{13}$

Other bleeding pattern in present study was frequent bleeding (14\%), intermenstrual bleeding (18\%), heavy prolonged $(6 \%)$ and irregular bleeding (12\%). This was comparable to Urvashi et al. ${ }^{14}$ In their study, they had polymenorrhoea in $(23 \%)$ of cases and metrorrhagia in $(19 \%)$ of cases. Shobhita GL et al also had polymenorrhagia in $25 \%$ of patients $(7 \%){ }^{13}$

In this study one patient who had ET >20 mm and had heavy menstrual bleeding, showed atypical endometrial hyperplasia on histopathology. Similarly, one patient with ET 15-19 mm had atypical endometrial hyperplasia.

\section{Endometrial thickness on TVS}

In my study on TVS at endometrial thickness 5 to $8 \mathrm{~mm}$, no endometrial pathology was found which was comparable with other studies Shobhitha GL et al also observed that no endometrium abnormality was found on ET $<8 \mathrm{~mm} .{ }^{13}$ Veena BT et al revealed normal endometrium in $45 \%$ (majority of these patients had endometrial thickness less than $9 \mathrm{~mm}) .{ }^{15}$

In most of studies it revealed that endometrial thickness of $8 \mathrm{~mm}$ could be taken as cut off in perimenopausal women and in present study the similar finding was observed.

\section{Abnormal endometrial finding on TVS}

In this study analysis of patient's findings on TVS were compared with endometrial finding and TVS finding was compared with histopathological findings. In present study, Endometrial hyperplasia by on TVS was found in 12 cases, on comparison with histopathology report 9 cases were truly diagnosed on TVS and 2 cases missed and 3 cases misdiagnosed out of which one was normal, one was endometrial polyp and one was adenomyosis on histopathology report.

Endometrial polyp was found on TVS in 7 cases, on comparison with histopathology, 5 cases identified as truly on TVS and 3 cases missed by TVS and 2 cases misdiagnosed out of which 1 case had normal endometrium and 1 case had endometrial hyperplasia on histopathology.

Sub mucosal fibroid was found on TVS in 4 cases. On comparison with histopathology 3 cases had sub mucosal fibroid and 1 case had normal endometrium on histopathology, and one case misdiagnosed as submucosal fibroid which was normal on histopathology.

On histopathology report 3 cases of adenomyosis were found, on TVS one case correctly diagnosed as adenomyosis and 2 cases missed out of which 1 was normal and 1 was endometrial hyperplasia on TVS and one case misdiagnosed as adenomyosis which was normal on histopathology.

Takreem et al reported $15 \%$ of cases of endometrial hyperplasia among 100 perimenopausal women. ${ }^{16}$ Slobada L et al showed endometrial hyperplasia in $22.6 \%$ cases, in the study by Dangal $\mathrm{G}$ et al, the incidence was $23 \% .^{17,18}$ which is in concordance with TVS findings in present study $24 \%$.

In present study the sensitivity, specificity, PPV, NPV for diagnosis of endometrial hyperplasia on TVS was 81.81 , $94.43 \%, 90 \%, 95 \%$ which correlated with findings of Shokouhi B. ${ }^{19}$ The accuracy, sensitivity, specificity, PPV, and NPV were $88.25 \%, 90.7 \%, 84 \%, 97.7 \%$, and $84 \%$ in premenopausal women in AUB patients specially in endometrial hyperplasia in their study. Aslam et al reported sensitivity and specificity of TVS $81.3 \%, 73.6 \%$ respectively. ${ }^{20}$

\section{Endometrial finding on hysteroscopy}

In present study, analysis of patients on hysteroscopic finding showed normal endometrium in $56 \%$ of patients and remaining $44 \%$ showed endometrial pathology.

In current study, hysteroscopy showed endometrial hyperplasia in $20 \%$ cases of AUB and other intrauterine pathology observed was polyp which was found in $16 \%$ of cases, sub mucosal fibroid in $8 \%$ of cases respectively.

Out of 8 cases of endometrial polyp all 8 were diagnosed on hysteroscopy and all 4 cases of sub mucosal fibroid was also diagnosed by it. It showed that hysteroscopy had very high sensitivity and specificity to diagnose intra uterine pathology such as polyp and sub mucosal fibroid as compared to TVS. These finding correlated with Sheetal et al, they showed hyperplasia in $18 \%$, endometrial polyp $9 \%$, and sub mucosal myoma $11 \% .^{21}$ 
In present study, the incidence of other pathological lesion such as polyp and sub mucosal fibroid correlated with the study by Veena BT et al it was seen that sub mucus fibroid found in $6.7 \%$ and polyps in $15 \%$ of cases by hysteroscopy. ${ }^{15}$ Similarly, Astudillo et al and Sciarra $\mathrm{JJ}$ et al also had similar pick up rates of the intra-cavitary lesions. ${ }^{22,23}$ In present study the sensitivity, specificity, PPV and NPV for endometrial hyperplasia on hysteroscopy was $72.72 \%, 94.87 \%, 88.88 \%, 92.5 \%$ respectively. Loverro et alstated the sensitivity, specificity, positive predictive value and negative predictive value was 98\%, 95\%, 63\% and $99 \%$, respectively, for endometrial hyperplasia. ${ }^{24}$
In present study the sensitivity, specificity, PPV, NPV was $100 \%$ for polyp and sub mucosal fibroid in hysteroscopy. It correlates with the findings of Sheetal et $\mathrm{al}^{64}$ in which sensitivity, specificity, positive predictive value and negative predictive value of hysteroscopy for endometrial polyp was $100 \%$.

Panda et al, Acharya $\mathrm{V}$ et al showed the sensitivity and specificity of hysteroscopy for sub mucous fibroid was $100 \% .{ }^{25,26}$ Sheetal et al showed the sensitivity, specificity, positive predictive value and negative predictive value of hysteroscopy for fibroid was $100 \%$ each. $^{21}$

Table 7: Overall efficacy of hysteroscopy with transvaginal sonography with other studies.

\begin{tabular}{|llllll|}
\hline Study & Procedure & Sensitivity & Specificity & PPV & NPV \\
\hline \multirow{2}{*}{ Urvashi et al } & TVS & 73.07 & 95.83 & 95 & 76.66 \\
\cline { 2 - 6 } Ritu Mishra et al & Hysteroscopy & 89.79 & 97.56 & 97.95 & 90.56 \\
\cline { 2 - 6 } & TVS & 73.9 & 73.7 & 73.70 & 73.8 \\
\cline { 2 - 7 } Present study & TVS & 78.3 & 84.7 & 85.4 & 81 \\
\cline { 2 - 7 } & Hysteroscopy & 76 & 94 & 76 & 94 \\
\hline
\end{tabular}

In the present study overall sensitivity, specificity, PPV, NPV of TVS were $76 \%, 94 \%, 76 \%$ and $94 \%$ respectively as compare to hysteroscopy which had overall sensitivity, specificity, PPV, NPV 89.36\%, 94.77\%, 84\% and $96.66 \%$. The sensitivity, specificity, PPV, NPV of present study fairly comparable with the study of Urvashi et al and Ritu et al. ${ }^{14,27}$

\section{CONCLUSION}

In conclusion, abnormal uterine bleeding which often prevails as an important and common gynecological ailment in my study $48 \%$ patient had normal endometrium, and $52 \%$ had abnormal uterine endometriual finding, out of which endometrial hyperplasia found in $22 \%$, polyp in $16 \%$, submucosal fibroid in $8 \%$, and adenomyosis in $6 \%$ of cases. Both TVS and hysteroscopy can detect endometrial intracavitary abnormalities with varying accuracies.

The sensitivity, specificity, PPV, NPV of TVS was $76 \%$, 94\%, 76\% and $94 \%$ and sensitivity, specificity, PPV, NPV of hysteroscopy was $89.36 \%, 94.77 \%, 84 \%$ and $96.66 \%$.

The result showed that Transvaginal sonography has a moderate diagnostic accuracy in detecting endometrial hyperplasia and other intrauterine pathology. TVS is safe, acceptable and easily available in most secondary and tertiary care setting and is noninvasive. It should be continued as 1st line diagnostic tool in patients with AUB in perimenopausal women.
The result showed that hysteroscopy has important tool in the diagnosis of various endometrial and intrauterine lesion, with high sensitivity, predictive value of a negative test and low false negativity

TVS and hysteroscopy should be employed hand in hand in evaluation of AUB after assessing the need and affordability of patient.

\section{ACKNOWLEDGMENTS}

Authors would like to acknowledge the Department of Anaesthesia and faculty of Department of Obstetrics and Gynecology, Mahatma Gandhi Hospital, Jaipur for their support during the study.

\section{Funding: No funding sources}

Conflict of interest: None declared

Ethical approval: The study was approved by the Institutional Ethics Committee

\section{REFERENCES}

1. Vilos GA, Tureanu V, Garcia M, Abu-Rafea B. The levonorgestrel intrauterine system is an effective treatment in women with abnormal uterine bleeding and anticoagulant therapy. J Minim Invasive Gynecol. 2009;16(4):480-4.

2. Euro pub med central PMID-10524483, Oriel KA, Shrageers university of wiscouin school of Medicine, Madison 53715, USA. American family physician 1999;6095:1371 -80, discussion 1381-2. 
3. Fraser IS, Langham S, Uhl-Hochgraeber K. Healthrelated quality of life and economic burden of abnormal uterine bleeding. Expert Rev Obstet Gynecol. 2009;4(2):179-89.

4. Munro MG, Critchley HO, Fraser IS, FIGO Menstrual Disorders Working Group. The FIGO classification of causes of abnormal uterine bleeding in the reproductive years. Fertil Steril. 2011;95(7):2204-8.

5. Lefebvre G, Vilos G, Allaire C, Jeffrey J, Arneja J, Birch C, Fortier M, Wagner MS. The management of uterine leiomyomas. J Obstet Gynecol Canada. 2003;25(5):396-418.

6. Özdemir S, Çelik Ç, Gezginç K, Kıreşi D, Esen H. Evaluation of endometrial thickness with transvaginal ultrasonography and histopathology in premenopausal women with abnormal vaginal bleeding. Arch Gynecol Obstet. 2010;282(4):395-9.

7. Fleischer AC, Kalemeris GC, Machin JE, Entman SS, James AE. Sonographic depiction of normal and abnormal endometrium with histopathologic correlation. J Ultrasound Medic. 1986;5(8):445-52.

8. Smith-Bindman R, Kerlikowske K, Feldstein VA, Subak L, Scheidler J, Segal M et al. Endovaginal ultrasound to exclude endometrial cancer and other endometrial abnormalities. JAMA. 1998;280(17):1510-7.

9. Ash SJ, Farrell SA, Flowerdew G. Endometrial biopsy in DUB. J Reprod Medic. 1996;41(12):892-6.

10. de Vries LD, Dijkhuizen FP, Mol BW, Brölmann HA, Moret E, Heintz AP. Comparison of transvaginalsonography, saline infusion sonography, and hysteroscopy in premenopausal women with abnormal uterine bleeding. J Clin Ultrasound. 2000;28(5):217-23.

11. Pillai SS. Sonographic and histopathological correlation and evaluation of endometrium in perimenopausal women with abnormal uterine bleeding. Int J Reprod Contracept Obstet Gynecol. 2014;3(1):113-7.

12. Arnold JA, Saravanan S. A two year clinicopathological study of non-gravid women with abnormal uterine bleeding in a rural tertiary care centre in Tamilnadu: In Concurrence with The Figo Recommendations. JEMDS. 2015;4(63):10990-1000.

13. Shobhitha GL, Kumari VI, Priya PL, Sundari BT. Endometrial study by TVS and It's correlation with histopathology in abnormal uterine bleeding. J Dental Med Sci. 2015;14(4):21-32.

14. Verma U, Garg R, Singh S, Yadav P, Rani R. Diagnostic approach in perimenopausal women with abnormal uterine bleeding. J SAFOMS. 2014;2(1):12.

15. Veena BT, Shivalingaiah N. Role of transvaginalsonography and diagnostic hysteroscopy in abnormal uterine bleeding. JCDR. 2014;8(12):OC06.
16. Takreem A, Danish N, Razaq S. Incidence of endometrial hyperplasia in 100 cases presenting with polymenorrhagia/menorrhagia in perimenopausal women. J Ayub Med Coll Abbotabad. 2009;21:60-3.

17. Sloboda L, Molnar E, Popovic Z, Zivkovic S. Analysis of pathohistological results from the uterine mucosa 1965-98 at the gynecology department in Senta. Med Pregl. 1999;52(6-8):263-5.

18. Dangal G. A study of endometrium in patients with abnormal uterine bleeding at Chitwan valley. K athmandu Univ Med J. 2003;1(2):110-2.

19. Shokouhi B. Role of transvaginal ultrasonography in diagnosing endometrial hyperplasia in pre-and postmenopause women. Nigerian Med J: J Nigeria Med Assoc. 2015;56(5):353

20. Aslam, Muhammad A, Lubnaljaz S, Tariq KS, Meher-un-Nisa, Rubina A, and Tahira K. Comparison of transvaginal sonography and saline contrast sonohysterography in women with abnormal uterine bleeding: correlation with hysteroscopy and histopathology. Int J Health Sci (Qassim). 2007;1(1):17-24.

21. Patil SG, Bhute SB, Inamdar SA, Acharya NS, Shrivastava DS. Role of diagnostic hysteroscopy in abnormal uterine bleeding and its histopathologic correlation. J Gynecol Endos Surg. 2009;1(2):98.

22. Neumann T, Astudillo J. Hysteroscopic study in patients with abnormal uterine bleeding. Revistachilena de obstetriciay ginecologia. 1993;59(5): 349-52.

23. Sciarra JJ, Valle RF. Hysteroscopy: a clinical experience with 320 patients. American journal of obstetrics and gynecology. 1977;127(4):340-8.

24. Loverro G, Bettocchi S, Cormio G, Nicolardi V, Porreca MR, Pansini N et al. Diagnostic accuracy of hysteroscopy in endometrial hyperplasia. Maturitas. 1996;25:187-91.

25. Panda A, Parulekar SV, Gupta A. Diagnostic hysteroscopy in abnormal uterine bleeding and histopathological correlation. J Obstet Gynecol India. 1999;49:74-6.

26. Acharya V, Mehta S, Randar A. Evaluation of dysfunctional uterine bleeding by TVS: Hysteroscopy and Histopathology. J Obstet Gynecol. 2003;53:170-7.

27. Mishra R, Misra AP, Mangal Y. To compare the result of TVS and SIS with hysteroscopy and histopathological examination in perimenopausal and postmenopausal bleeding. J Evol Med Dental Sci. 2015;4(7):1230-7.

Cite this article as: Choudhary J, Acharya V, Jain M. Evaluation of abnormal uterine bleeding with transvaginal sonography and hysteroscopy in perimenopausal women. Int J Reprod Contracept Obstet Gynecol 2017;6:3607-13. 